\title{
Milk ejection disorders in Swiss dairy cows: a field study
}

\author{
Claire J Belo ${ }^{1}$, Sabrina Schlegel ${ }^{2}$, Jürg Moll ${ }^{3}$, Erich Möstl ${ }^{4}$ and Rupert M Bruckmaier ${ }^{1 *}$ \\ ${ }^{1}$ Veterinary Physiology, Vetsuisse Faculty, University of Bern, Bremgartenstrasse 109a, 3001 Bern, Switzerland \\ ${ }^{2}$ Swiss Federal Institute of Technology Zurich, Rämistrasse 101, 8092 Zurich, Switzerland \\ ${ }^{3}$ Swiss Brown Cattle Breeders' Federation, Chamerstrasse 56, 6300 Zug, Switzerland and ASR, Villettemattstrasse 9, Postfach 3000 \\ Bern 14, Switzerland \\ ${ }^{4}$ Institute of Biochemistry, Department of Natural Sciences, University of Veterinary Medicine, Veterinaerplatz 1, 1210 Vienna, Austria
}

Received 27 June 2008; accepted for publication 26 November 2008; first published online 13 March 2009

\begin{abstract}
A questionnaire was sent to 2099 dairy farms to investigate the occurrence of poor milkability. Based on that, the frequency of poor milkability in Swiss dairy cows was $4 \%$ and the percentage of cows treated with oxytocin (OT) was $2 \%$. In addition, 270 dairy farms that had reported cases of animals with poor milkability were contacted for an interview to classify the disorders. Farmers suspected disturbed milk ejection in $52 \%$, anatomical dysfunction of the teat and/or the udder in $16 \%$ and milk ejection disorder or impaired milkability caused by discernable environmental factors in $32 \%$ of the cases. Forty-eight animals from 18 farms with suspected milk ejection disorders were selected for an experimental field study which included milk flow recording and OT administration to induce milk ejection. After cessation of the spontaneous milk flow, a low dose of OT $(0 \cdot 2,0.5$ or 1 i.u. $)$ was injected i.v. to test the responsiveness of the udder to OT at a physiological level. When milk flow ceased again, 10 i.u. OT was injected i.v. (supraphysiological) to ensure complete udder emptying and to determine the residual milk. Milk ejection disorder could be confirmed in $69 \%$ of the cases, i.e. if residual milk was $>20 \%$ of the total milk. Because in $27 \%$ of the animals milk ejection disorder was not confirmed on the basis of elevated residual milk, an anatomical disorder of the teat and/or the udder was suspected. Milk ejection disorder could be confirmed in $69 \%$ of the cases whereas in $27 \%$ of the suspected cases an anatomical disorder of the teat and/or the udder was suspected. An increased cortisol production in cows with milk ejection disorder was not obvious because faecal concentrations of cortisol metabolites with a $5 \beta$-androstane$3 \alpha, 11$ oxo-structure were not augmented in animals with disturbed milk ejection.
\end{abstract}

Keywords: Poor milkability, anatomical abnormality, milk flow.

A rapid and complete milk removal during machine milking is important to maintain a high milk production level and good udder health. Activation of the milk ejection reflex and its maintenance throughout milking is required in order to achieve complete udder evacuation (Mayer et al. 1984; Bruckmaier et al. 1994). Milk ejection is induced by tactile stimulation of the teat (Sagi et al. 1980; Mayer et al. 1991; Gorewit et al. 1992) which causes release of oxytocin (OT) from the posterior pituitary and hence myoepithelial contraction in the alveolar tissue of the mammary gland (Soloff et al. 1980; Bruckmaier \& Blum, 1996). Due to this contraction, the alveolar milk is shifted

*For correspondence; e-mail : rupert.bruckmaier@physio.unibe.ch into the cisternal cavities where it becomes available for the milking machine.

Milk removal can be disturbed either by a dysfunction of the milk ejection reflex (reviewed by Bruckmaier \& Blum, 1998) or by anatomical abnormality or previous teat injuries (Querengässer et al. 1999) which lead to decreased milk flow and milk yield in the affected teat (Querengässer et al. 2002).

Milk ejection disorders are caused by reduced or totally lacking OT release (Bruckmaier et al. 1992; Bruckmaier et al. 1994) or altered responsiveness to OT at the level of the mammary gland as it is seen after chronic injection of exogenous OT (Bruckmaier, 2003; Macuhova et al. 2004). Inhibition of OT release was shown to occur under various conditions such as during milking in unfamiliar surroundings (Bruckmaier et al. 1992, 1993; Macuhova et al. 2002) 
during peak oestrus and after changing from calf suckling to machine milking (Tancin et al. 1995). In such cases, plasma $\beta$-endorphin was elevated, and endogenous opioid peptides are suspected but not proven to be involved in the inhibition of OT release (Bruckmaier et al. 1993, 1996; Macuhova et al. 2002). On the contrary, feeding during milking is reported to influence positively milk flow and milk production (Brandsma, 1978; Samuelsson et al. 1993; Svennersten et al. 1995). It has also been shown that feeding before or during milking caused an enhanced milking-related OT release (Johansson et al. 1999).

Milk flow disorders based on anatomical dysfunction and disturbed milk ejection cause both economic loss by decreased milk production and increased susceptibility to intramammary infection (Agger \& Hesselholdt, 1986). Dairy farmers in European countries increasingly report cases of cows with disturbed milk removal. In these cases either the udder emptying takes a very long time or the main milk fraction cannot be completely removed.

The aim of this study was to estimate the frequency of poor milkability in the major breeds of Swiss dairy cattle, Brown Swiss (BS), Holstein (HO) and Red Holstein $x$ Simmental (SI), and to classify these disorders as anatomical or pathophysiological. Within the study, the farmers' diagnoses were verified experimentally and their specific activities to solve the problem were recorded.

\section{Materials and Methods}

The study was conducted in three steps. Questionnaires about poor milkability were sent to Swiss dairy farms (step I) and, after most of the questionnaires had been returned, 270 dairy farms that had reported poor milkability were additionally contacted by telephone, and details of the reported disorder and the specific activities performed by the farmers in order to solve the problem were investigated (step II). Finally, 48 cows located in 18 dairy farms were selected for the experimental part of the study (step III).

\section{Step I: questionnaires}

Questionnaires were sent in March 2007 to 2099 Swiss dairy farms which kept at least 25 dairy cows representing one or more of the major breeds in Switzerland (BS, HO, and $\mathrm{SI}$ ). The questionnaire consisted of 9 multiple choice questions and an additional space for free comments raised by the farmers. The questionnaire contained general questions about the dairy farms: number of animals, breeds, housing conditions and milking system. In addition specific questions were asked about cows with poor milkability: number of cows with poor milkability, number of cows regularly treated with OT injections, lactation number (primiparous $v$. multiparous) and stage of lactation (during or after the first week of lactation) when the problem commenced.
The effect of breed, herd size, housing condition and milking system on milkability was evaluated using the MIXED procedure of SAS (SAS Institute Inc., 2001). The model included percentage of animals with poor milkability within herd, herd size, breed, housing condition and milking system. Differences among least square means were considered statistically significant at $P<0.05$ using the Tukey option.

\section{Step II: telephone contact}

Among the farms that had reported poor milkability in the questionnaire, 270 farms (130 BS, $38 \mathrm{HO}$ and $102 \mathrm{SI}$ ) were randomly chosen and contacted by telephone in the period from June 2007 to February 2008. Further information was sought about the cows mentioned with poor milkability in the questionnaire. Particular attention was paid to the number of farms that had sold the problem animals in the meantime; the suspicion (according to the farmer) of a morphological dysfunction of the teat and/or the udder or a disturbed milk ejection; the actual lactation number and stage of lactation of the cows as well as their lactation number and stage when the problem commenced. Finally, details of the specific activities performed by the farmers in order to solve the problem were asked for.

\section{Step III: milking experiment}

Based on the questionnaire (step I) and additional telephone interviews (step II), 48 cows for which disturbed milk ejection had been reported and were declared clinically healthy by the farmers were selected for the experimental part of this study. The criterion of selection was the suspicion by the farmer that $<80 \%$ of the stored milk could be removed during routine machine milking without OT injection. Animals were not used for the experiment in the case of suspected disturbed milk ejection caused by any type of disorders of the milking technology (suspected technical disorder by the farmer or $>25 \%$ of the animals in the same herd treated with OT). Dairy farms with automatic or carousel milking systems were excluded from the study for technical reasons (difficult experimental handling).

All the problem cows (24 BS, $10 \mathrm{HO}$ and $14 \mathrm{SI})$ were in their first to eighth lactation and in lactation months 1-10 except for 5 cows that were in extended lactation (month 12-36) and not pregnant. The cows were located in 18 dairy farms in the states of Fribourg, Bern and Lucerne where also the experiments were conducted. On the days of the experiment, the animals stayed in their usual environment and received their usual diet. Cows were experimentally milked during the routine milking time and with their habitual milking system. Foremilking, teat cleaning and udder preparation were performed by the farmers according to their usual routine. A continuous milk flow pattern was recorded during one entire milking process with a mobile milk flow recording unit (LactoCorder ${ }^{\circledR}$, 
WMB AG, Balgach, Switzerland). After cessation of spontaneous milk flow, the cows were injected i.v. with one single physiological dose of OT based on previous studies (Labussière \& Durand, 1970; Bruckmaier et al. 1994; Lollivier \& Marnet, 2005) $(0 \cdot 2,0.5$ or 1 i.u., Oxytocin Stricker $^{\circledR}$, Werner Stricker AG, Zollikofen, Switzerland). The aim of these injections was to mimic release of OT during milking and to test the responsiveness of the udder to lower $(0 \cdot 2$ i.u. $)$, medium ( 0.5 i.u. $)$ and upper ( 1 i.u. $)$ physiological concentrations of OT. The dose $(0 \cdot 2,0 \cdot 5$ or 1 i.u.) was randomly chosen for each individual animal. In order to obtain these low dosages of OT in a volume which could be easily injected, the commercial OT (10 i.u. $/ \mathrm{ml})$ was diluted $1: 100$ in sterile saline $(0.9 \%)$ before injection. When the milk flow as induced by exogenous OT ceased, 10 i.u. OT was injected i.v. (undiluted product) to ensure complete emptying of the udder including residual milk, which requires a supraphysiological concentration of OT also in healthy cows. The amount of residual milk was measured and, according to Bruckmaier (2003), was considered as pathological when its fraction amounted to $>20 \%$ of the total milk yield.

Eleven control animals with normal milk ejection and comparable production levels $(2 \mathrm{BS}, 3 \mathrm{HO}$ and $6 \mathrm{SI}$ in lactation numbers 2-7 and in lactation months 1-12) were used to test and confirm the physiological range of residual milk. Five cows were located in five barns where also cows with disturbed milk ejection were investigated, and six cows were from the dairy herd of the Swiss Federal Research Station at Posieux (ALP), respectively. The experimental procedure was similar to that used for the problem animals, except that the control cows were only injected i.v. with 10 i.u. OT (no low dosage) after cessation of spontaneous milk flow.

Faecal samples for the determination of a group of cortisol metabolites with a $5 \beta$-androstane- $3 \alpha, 11$ oxo-structure $(3 \alpha, 11$ oxo-A) (Möstl et al. 2002) were collected from the rectum, after milking, from all the cows tested for disturbed milk ejection and from 14 control animals (5 BS, $3 \mathrm{HO}$ and $6 \mathrm{SI}$ ) with normal milk ejection, located in 14 barns where also animals with disturbed milk ejection were investigated. Samples were conserved at about $5{ }^{\circ} \mathrm{C}$ for a maximum of $3 \mathrm{~h}$ until they were stored at $-20^{\circ} \mathrm{C}$ for later analysis.

After the results of the milking experiment had been analysed, 15 cows with normal milkability or with poor milkability due to anatomical dysfunction were excluded from this part of the study.

The data of residual milk fractions and $3 \alpha, 110 x 0-A$ concentrations are presented as means \pm SEM. The difference in terms of percentage of residual milk between the three groups of cows (control cows, cows with milk ejection disorder and cows falsely assumed by the farmers to have milk ejection disorder) was tested using the the MIXED procedure of SAS (SAS Institute Inc., 2001). The model included group and milk production at
Table 1. Incidence of poor milkability in Swiss dairy cows traced with the questionnaires (Step I). (BS: Brown Swiss; SI: Red Holstein $\times$ Simmental; HO: Holstein)

\begin{tabular}{lllll} 
& BS & SI & HO & \multicolumn{1}{l}{ Total } \\
& & & & \\
Number of cows recorded & 29119 & 28044 & 10385 & 67548 \\
Poor milkability & & & & \\
$\quad$ Number of cows & 1484 & 879 & 279 & 2642 \\
$\quad$ Cows, \% & 5 & 3 & 3 & 4 \\
$\quad$ Treated with OT, \% & 50 & 40 & 40 & 45
\end{tabular}

the experimental milking as covariable. Differences among least square means were considered statistically significant at $P<0 \cdot 05$ using the Tukey test.

For $3 \alpha, 11$ oxo-A, problem animals were compared with control animals by Student's $t$ test and a difference was considered significant at a level of $P<0 \cdot 05$.

\section{Results}

\section{Step I: questionnaires}

From the 2099 questionnaires sent, 1563 were returned within 1 month. Out of them, 839 (415 BS, $90 \mathrm{HO}$ and $334 \mathrm{SI})$ dairy farms had reported poor milkability.

The percentage of returned questionnaires was almost similar in all breeds (BS: $78 \%, \mathrm{HO}: 72 \%$ and $\mathrm{SI}: 72 \%$ ). The percentage of cows affected by poor milkability was nearly similar in all three breeds (Table 1). Exogenous OT was frequently used for milk removal in cows with poor milkability (Table 1). However, out of all recorded animals (covered by the returned questionnaires) only $2 \%$ had been treated with OT.

Among the cows recorded as affected by poor milkability in the questionnaires, $21 \%$ were primiparous and $38 \%$ multiparous. The lactation number was not specified for $42 \%$ of the cows with reported poor milkability. Eighty-eight percent of the primiparous cows with reported poor milkability were in the first week of lactation while only $4 \%$ were in later periods of lactation. In contrast, of the multiparous animals with poor milkability, $17 \%$ were in the first week of lactation and $51 \%$ were in later stages of lactation. Stage of lactation was not specified in $8 \%$ of the primiparous and $32 \%$ of the multiparous animals.

No relation was found between poor milkability, breed, herd size and housing condition (free-stall $v$. tie-stall) whereas the milking system had a slight effect on poor milkability $(P=0 \cdot 04)$. Among the most used milking systems in Switzerland, the percentage of animals with poor milkability per herd was from $3 \cdot 3 \pm 0.9 \%$ with bucket milking, $3 \cdot 0 \pm 0 \cdot 3 \%$ with pipe-line milking plant and from $3 \cdot 8 \pm 0 \cdot 3 \%, 5 \cdot 0 \pm 0 \cdot 4$ and $5 \cdot 6 \pm 0 \cdot 8 \%$ in tandem, herringbone and side by side milking systems, respectively. 


\section{Step II: telephone contacts}

The 270 dairy farms selected for an additional contact corresponded to $30 \%$ of the BS, $42 \%$ of the $\mathrm{HO}$ and $31 \%$ of the SI dairy farms that had reported cows with poor milkability in the questionnaire.

Forty-seven percent of the dairy farms had already culled or sold the problem $\operatorname{cow}(\mathrm{s})$ before the interview. Finally, specific information was obtained on a total of 297 cows with poor milkability. Out of these 297 cows, suspected disturbed milk ejection was reported by the farmers in 154 cases, i.e. in 52\%, of the cows with poor milkability. Cows reported with milk ejection disorder were mostly multiparous (72\%).

Apart from disturbed milk ejection, anatomical dysfunction of the teat and/or udder was reported in $16 \%$ of the cases (i.e. in 47 cows) and external factors disturbing milk ejection or impairing milkability such as engine disturbance, stray voltage and animal diseases were reported for 96 cows, i.e. in $32 \%$ of the cases.

Ten percent of the 297 cows with poor milkability suffered only transiently from the disturbance. These animals no longer showed any disorder of milk removal at the time of the telephone contact.

Apart from using OT $(65 \%$ of the dairy farms with problem animals) other activities frequently performed to improve the milkability of the cows were vaginal stimulation $(11 \%)$, i.e. massage of the vulva and the vagina, air blown into the vagina or transrectal massage of the uterus; intensive stimulation of the teats and stripping (14\%). Marginally, feeding during milking and homeopathic treatments were reported as treatments to overcome poor milkability.

\section{Step III: milking experiment}

The amounts of spontaneously removed milk and the milk removed in response to OT administration (residual milk) of 48 cows with suspected disturbed milk ejection were recorded. The cows were located in 18 dairy farms and were mostly kept in free-stall housing conditions (14 dairy farms). The number of cows per farm was $46 \cdot 8 \pm 3 \cdot 4$ cows. Mean milk production per cow was $7655 \pm 180 \mathrm{~kg}$ and the percentage of cows reported with poor milkability was $6 \cdot 4 \pm 1 \cdot 5 \%$ per farm, i.e. in most cases one single animal.

The 48 problem cows and the 11 control cows had similar average lactation number $(3 \cdot 8 \pm 0 \cdot 2$ and $3 \cdot 9 \pm 0 \cdot 6$, respectively), were almost in the same stage of lactation ( $200 \pm 28$ and $192 \pm 47$ days of lactation, respectively) and produced $14 \cdot 1 \pm 0 \cdot 7$ and $11 \cdot 3 \pm 1 \cdot 1 \mathrm{~kg}$ of milk during the experimental milking, respectively. Seventy-four percent of the 48 cows with reported poor milkability were treated with OT. Control cows were never treated with OT.

The presence of a disturbance of milk ejection (Fig. 1b) which had been suspected by the farmer was confirmed by the experiment in 33 cases, i.e. in $69 \%$ of the tested cows. Contrary to the farmers' assumption, in 13 cases $(27 \%$ of
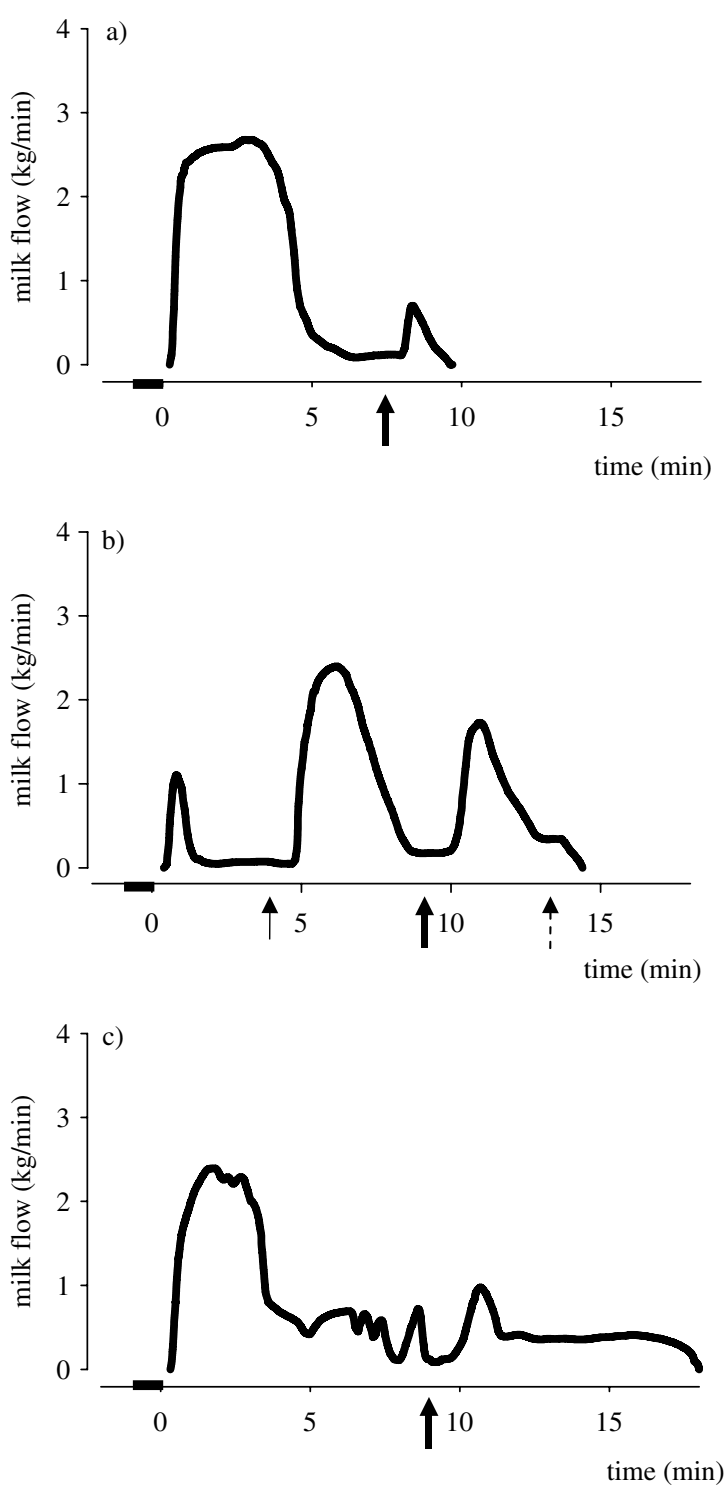

Fig. 1. Milk flow in: (a) a representative cow with normal milk ejection without and with injection of $10 \mathrm{i} . \mathrm{u}$. oxytocin; (b) a representative cow with disturbed milk ejection with injections of $0.5 \mathrm{i} . u$. and $10 \mathrm{i} . \mathrm{u}$. oxytocin after cessation of spontaneous milk flow; (c) a representative cow with anatomical disorder before and after injection of 10 i.u. oxytocin.

$$
\begin{aligned}
& \text { : Preparation } \\
& \text { : } 0.5 \text { i.u. oxytocin } \\
& \text { : } 10 \text { i.u. oxytocin }
\end{aligned}
$$

the tested cows) disturbed milk ejection was excluded because a minimum of $80 \%$ stored milk was spontaneously available; the characteristics of the milk flow curves were compatible with anatomical dysfunction of the teats and/or the udder (Fig. 1c). In only two cases (4\% of the tested cows) milk removal and the shape of the milk 


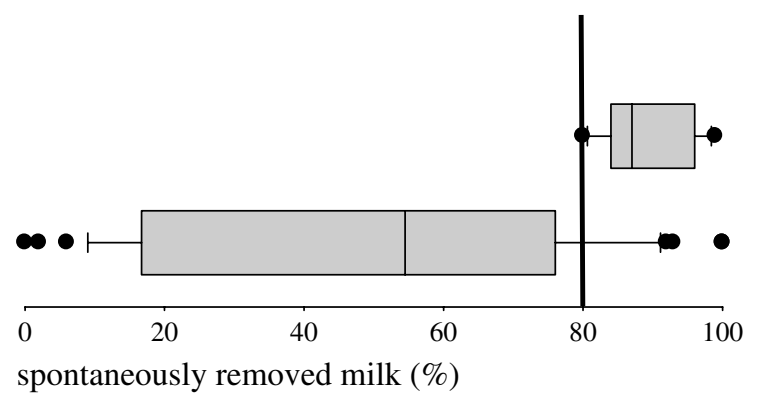

Fig. 2. Box-Whisker-Plot with the percentages of spontaneously removed milk (milking experiment, Step III) in control animals (upper box, $n=11$ ) and cows suspected for disturbed milk ejection (lower box; $n=48$ ). The boxes represent $50 \%$ of the values between the lower and upper quartiles, and the median. The whiskers represent the $5 \%$ and $95 \%$ quantiles, i.e. between the whiskers $90 \%$ of the values are located, and the outliers are represented by dots.

flow curve were totally normal despite the farmers' suspicion of disturbed milk ejection (Figs 1a and 2).

The residual milk fraction differed widely (Fig. 2) among the cows with detected milk ejection disorder (mean $65 \pm 4 \%$ ) whereas it was $11 \pm 2 \%$ in the cows falsely assumed by the farmers to have disturbed milk ejection, and $11 \pm 2 \%$ of the total milk in the control cows. The difference in terms of residual milk was not significant between control cows and cows falsely assumed by the farmers to have disturbed milk ejection. However, cows with detected milk ejection disorder had significantly $(P<0 \cdot 0001)$ more residual milk than control cows and cows falsely assumed by the farmers to have disturbed milk ejection. Milk production had no effect on the percentage of residual milk.

Among the 33 cows with detected milk ejection disorder, the milk fraction spontaneously ejected was $<30 \%$ in $54.5 \%$ of the cows, whereas in $45.5 \%$ of the cows the spontaneously removed milk was $30-80 \%$. A milk ejection response to a low OT dosage $(0 \cdot 2,0 \cdot 5$ or 1 i.u. $)$ could be shown in 31 of 33 cows, while 2 animals did not react at a dosage of $0 \cdot 2$ i.u. OT.

Among the cows with disturbed milk ejection, eight suffered from another disease (i.e. had probably subclinical infection with Staphylococcus aureus or showed lesions of former cow pox) which may have induced pain during milking and thus have impaired the release of OT. Five cows were in lactation month 12-36 and were not pregnant owing to fertility problems.

The major portion (27) of the tested cows was in the second to fourth lactation while 19 cows were past the fourth lactation and only two cows were in the first lactation. According to the information obtained in step II, poor milkability commenced mostly (35 cases) immediately post partum, in three cases in the first three weeks post partum, another three in the first three months post partum, and in only one case at a later stage of lactation.
For six animals, the stage of lactation at which the problem commenced was unknown. The commencement of the disturbance was in the first lactation in 17 animals, in the second to fourth lactation in 20, and in the fourth lactation only in one animal.

\section{Cortisol metabolites}

Measurement of the $3 \alpha, 11$ oxo-A concentration failed for one control and one problem animal so that the mean values were calculated with 32 problem animals and 13 control animals. The $3 \alpha, 11$ oxo-A concentration (freshmatter basis) in the faeces of the control animals was $140 \pm 24 \mathrm{ng} / \mathrm{g}$ and was not significantly different from that of the problem animals $(150 \pm 12 \mathrm{ng} / \mathrm{g})$.

\section{Discussion}

The very high percentage of returned questionnaires clearly demonstrated the deep interest in the problem among the farmers in this study and the importance attached to milkability in dairy practice. Besides the direct economic consequences caused by poor milkability during each milking, it needs to be considered also that about half of the dairy farms culled the animals affected by poor milkability during the ongoing lactation, which means an even more serious economic loss.

In the case of disturbed milk ejection, the most frequently performed activity to improve milkability was the injection of exogenous OT. Activities to enhance the endogenous release of OT such as blowing air into the vagina or transrectal massage of the uterus were only marginally used, probably because OT injections are very rapidly effective, simple and inexpensive, and allow a total removal of the milk. If a high OT dosage is used the milk removed even includes residual milk which would not be available during normal milking in healthy cows. On the other hand, chronic use of OT in a high dosage desensitizes the udder to OT and it is difficult to stop the treatment (Bruckmaier, 2003; Macuhova et al. 2004). Therefore, OT can turn from a therapeutic drug to overcome disturbed milk ejection into a new cause of disturbed milk ejection if used chronically. Disturbed milk ejection caused by chronic administration of high dosage OT occurs not at the level of OT release, as does the spontaneously disturbed milk ejection, but is based on a decreased response of OT at the level of the mammary gland (Macuhova et al. 2004).

When the disturbed milk ejection was still present after the first week of lactation, about $50 \%$ of the farmers decided to cull the cows, especially primiparous animals. This result corroborated the opinion that udder disorders occurring before the peak of lactation represent a high risk for culling (Beaudeau et al. 1995).

Disturbances of milk ejection have been described either in primiparous cows that have not been milked before (Bruckmaier et al. 1992; Van Reenen et al. 2002) or in 
multiparous dairy cows milked in uncomfortable situations (Lefcourt \& Akers, 1982; Blum et al. 1989) or in unfamiliar surroundings (Bruckmaier et al. 1993, 1996). In the present study we have shown that disturbed milk ejection also occurred during routine milking in multiparous cows in different stages of lactation. Moreover, similarly to primiparous animals, a non-negligible percentage of multiparous cows was reported to suffer from disturbed milk ejection during the first days after calving. The lower percentage of multiparous than of primiparous cows affected by milk ejection disorder immediately after calving could suggest the existence of individual differences in behavioural and physiological responsiveness among dairy cows during transition from the dry period to lactation. There was no relation of disturbed milk ejection and breed, herd size or housing condition (free-stall or tie barn farms) but a slight influence of the milking system on the milkability was found. Although farms using a herringbone or a side by side milking system showed a higher percentage of cows per herd with poor milkability, the significant effect of milking system $(P=0.04)$ could not be attributed to specific systems by statistical testing. In this study, no difference in the occurrence of milk ejection disorder was found within the major breeds of dairy cows in Switzerland.

The percentage of residual milk differed widely among the cows tested for milk ejection disorder. In $45.5 \%$ of the cases, $>30 \%$ of the total milk amount was spontaneously available, which indicated a transient release or a release of OT below the threshold (Bruckmaier et al. 1994). In the case of OT release being totally lacking, only the cisternal fraction, i.e. not more than $30 \%$ of the milk (Pfeilsticker et al. 1996; Ayadi et al. 2004) would have been available spontaneously. Furthermore, $94 \%$ of the cows with milk ejection disorder were responsive to a physiological dose of OT. We assumed that according to Lollivier \& Marnet (2005) there were individual differences in the physiological concentration of OT needed to mimic natural events, so that the applied dose was in two cases insufficient. Both the transient release of OT and the udder responsiveness to physiological OT doses supported the hypothesis that the inhibition of the milk ejection depends on an inhibition of OT release from the pituitary (Bruckmaier et al. 1992).

The fact that $31 \%$ (i.e. 15 cows) of the cows declared by the farmers as having milk ejection disorder suffered from anatomical disorder or had no disorder at all demonstrated clearly the difficulty in differentiating between anatomical disorder of the teat or the udder and pathophysiological disorder, without adequate technical equipment (milk flow recording unit) and experimental OT administration as used in our experiment. In this study the residual milk fraction amounted to $0-20 \%$ of the total milk yield when milk ejection was normal, confirming previous results (Bruckmaier, 2003).

The measured $3 \alpha, 11$ oxo-A concentrations in faeces was almost similar between control cows and those with disturbed milk ejection. Obviously the animals suffering from milk ejection disorder were not undergoing a particular stress as mediated by an enhanced release of cortisol (Palme et al. 2000). Nevertheless, the results did not furnish any information about the stress status of the animals during milking.

In conclusion disturbed milk removal occurs in Swiss dairy cows at a frequency of $4 \%$ independent of breed and $2 \%$ of the cows are permanently or punctually treated for disturbed milk ejection due to a lack of OT release. However, without technical equipment to record milk fractions and milk flow it is difficult for the farmer to judge correctly whether a disturbed milk ejection is the cause for the disturbance. To be sure, cows under suspicion should be checked for milk ejection and residual milk by specially educated persons in order to obtain valid data.

This study was supported by a grant of the Arbeitsgemeinschaft Schweizer Rinderzüchter (ASR) Bern, Switzerland. The support of the Swiss Brown Cattle Breeders' Federation, the Swiss Federation of Simmental Fleckvieh and the Swiss Federation of Holstein Cattle Breed is gratefully appreciated. We thank Nicole Stocker and Jakob Sauser for their hospitality and support during the experimental part of the study.

\section{References}

Agger JF \& Hesselholdt M 1986 Epidemiology of teat lesions in a dairy herd. II. Association with subclinical mastitis. Nordisk Veterinaermedicin 35 220-232

Ayadi M, Caja G, Such X, Rovai M \& Albanell E 2004 Effect of different milking intervals on the composition of cisternal and alveolar milk in dairy cows. Journal of Dairy Research 71 304-310

Beaudeau F, Ducrocq V, Fournichon C \& Seegers H 1995 Effect of disease on length of productive life of French Holstein dairy cows assessed by survival analysis. Journal of Dairy Science 78 103-117

Blum JW, Schams D \& Bruckmaier RM 1989 Catecholamines, oxytocin and milk removal in dairy cows. Journal of Dairy Research $\mathbf{5 6}$ $167-177$

Brandsma S 1978 The relation between milking, residual milk and milk yield. Proceedings, Annual Meeting National Mastitis Council 17 47-56

Bruckmaier RM, Schams D \& Blum JW 1992 Aetiology of disturbed milk ejection in parturient primiparous cows. Journal of Dairy Research $\mathbf{5 9}$ 479-489

Bruckmaier RM, Schams D \& Blum JW 1993 Milk removal in familiar and unfamiliar surroundings: concentrations of oxytocin, prolactin, cortisol and $\beta$-endorphin. Journal of Dairy Research $60449-456$

Bruckmaier RM, Schams D \& Blum JW 1994 Continuously elevated concentrations of oxytocin during milking are necessary for complete milk removal in dairy cows. Journal of Dairy Research 61 323-334

Bruckmaier RM \& Blum JW 1996 Simultaneous recording of oxytocin release, milk ejection and milk flow during milking of dairy cows with and without prestimulation. Journal of Dairy Research 63 201-208

Bruckmaier RM, Pfeilsticker HU \& Blum JW 1996 Milk yield, oxytocin and beta-endorphin gradually normalize during repeated milking in unfamiliar surroundings. Journal of Dairy Research 63 191-200

Bruckmaier RM \& Blum JW 1998 Oxytocin release and milk removal in ruminants. Journal of Dairy Science 81 939-949

Bruckmaier RM 2003 Chronic oxytocin treatment causes reduced milk ejection in dairy cows. Journal of Dairy Research $70123-126$ 
Gorewit RC, Svennersten K, Butler WR \& Uvnäs-Moberg K 1992 Endocrine responses in cows milked by hand and machine. Journal of Dairy Science 75 443-448

Johansson B, Uvnäs-Moberg K, Knight CH \& Svennersten-Sjaunja K 1999 Effect of feeding before, during and after milking on milk production and the hormones oxytocin, prolactin, gastrin and somatostatin. Journal of Dairy Research 66 151-163

Labussière J \& Durand A 1970 Intramammary pressure in cows after stimulation of the teat or after injection of oxytocin in the jugular vein. Annales de Zootechnie 19 385-397

Lefcourt AM \& Akers RM 1982 Endocrine response of cows subjected to controlled voltages during milking. Journal of Dairy Science $\mathbf{6 5}$ 2125-2130

Lollivier V \& Marnet P-G 2005 Galactopoietic effect of milking in lactating Holstein cows: role of physiological doses of oxytocin. Livestock Production Science 95 131-142

Macuhova J, Tancin V, Kraetzl W-D, Meyer HHD \& Bruckmaier RM 2002 Inhibition of oxytocin release during repeated milking in unfamiliar surroundings: the importance of opioids and adrenal cortex sensitivity. Journal of Dairy Research 69 63-73

Macuhova J, Tancin V \& Bruckmaier RM 2004 Effects of oxytocin administration on oxytocin release and milk ejection. Journal of Dairy Science 87 1236-1244

Mayer H, Schams D, Worstorff H \& Prokopp A 1984 Secretion of oxytocin and milk removal as affected by milking cows with and without manual stimulation. Journal of Endocrinology 130 355-361

Mayer H, Bruckmaier RM \& Schams D 1991 Lactational changes in oxytocin release, intramammary pressure and milking characteristics in dairy cows. Journal of Dairy Research 58 159-169

Möstl E, Maggs JL, Schrötter G, Besenfelder U \& Palme R 2002 Measurement of cortisol metabolites in faeces of ruminants. Veterinary Research Communicaton 26 127-139

Palme R, Robia C, Baumgartner W \& Möstl E 2000 Transport stress in cattle as reflected by an increase in faecal cortisol metabolites. Veterinary Record 146 108-109
Pfeilsticker HU, Bruckmaier RM \& Blum JW 1996 Cisternal milk in the dairy cow during lactation and after preceding teat stimulation. Journal of Dairy Research 63 509-515

Querengässer K, Geishauser T \& Nitschke M 1999 Investigation of teat canal length and milking disorders. Praktischer Tierarzt 80 796-804

Querengässer J, Geishauser T, Querengässer K, Bruckmaier RM \& Fehlings K 2002 Investigations on milk flow and milk yield from teats with milk flow disorders. Journal of Dairy Science 85810 817

Sagi R, Gorewit RC, Merrill WG \& Wilson DB 1980 Premilking stimulation effects on milking performance and oxytocin and prolactin release in cows. Journal of Dairy Science 63 800-806

Samuelsson B, Emanuelson M, Olsson G, Uvnäs-Moberg K \& Svennersten-Sjaunja K 1993 Hormonal profiles, rumen volatile fatty acids and milk trans-C18: 1 fatty acids in relation to milk fat content in restricted or ad libitum fed dairy cows. Acta Agriculturae Scandinavica $4876-56$

SAS 2001 SAS Institute Inc. Version 8.02., Cary NC, USA

Soloff MS, Chakraborty J, Sadhukan P, Senitzer D, Wieder M, Fernstrom MJ et al. 1980 Purification and characterization of mammary myoepithelial and secretory cells from the lactating rat. Endocrinology 160 887-899

Svennersten K, Gorewit RC, Sjaunja LO \& Uvnäs-Moberg K 1995 Feeding during milking enhances milking-related oxytocin secretion and milk production in dairy cows whereas food deprivation decreases it. Acta Physiologica Scandinavica 153 309-310

Tancin V, Harcek L, Broucek J, Uhrincat M \& Mihina St 1995 Effect of suckling during early lactation and changeover to machine milking on plasma oxytocin and cortisol levels and milking characteristics in Holstein cows. Journal of Dairy Research 62 249-256

Van Reenen CG, Van der Werf JT, Bruckmaier RM, Hopster H, Engel B, Noordhuizen JP \& Blokhuis HJ 2002 Individual differences in behavioral and physiological responsiveness of primiparous dairy cows to machine milking. Journal of Dairy Science 85 2551-2561 